\title{
LONG-TERM (1948-2006) SIMULATION OF SNOW DEPTH AT YAGISAWA DAM SITE USING JP10 REANALYSIS AND ENERGY BALANCE SNOW MODEL (WEB-DHM-S)
}

\author{
Maheswor SHRESTHA ${ }^{1}$, Toshio KOIKE ${ }^{2}$, Lei WANG ${ }^{3}$ and Kei YOSHIMURA 4 \\ ${ }^{1}$ Member of JSCE, Ph. D., Visiting Researcher, \\ Dept. of Civil Eng., the University of Tokyo (Bunkyo-ku, Tokyo, 113-8656, Japan) \\ ${ }^{2}$ Member of JSCE, Dr. Eng., Professor, \\ Dept. of Civil Eng., the University of Tokyo (Bunkyo-ku, Tokyo, 113-8656, Japan) \\ ${ }^{3}$ Member of JSCE, Dr. Eng., Professor, \\ Inst. of Tibetan Plateau Research, Chinese Academy of Sciences, (Beijing, 100085, China) \\ ${ }^{4}$ Member of JSCE, Dr. Eng., Assoc. Professor, \\ Atmosphere Ocean Research Institute, the University of Tokyo (Kashiwanoha, Chiba, 277-8568, Japan)
}

\begin{abstract}
A physically based distributed biosphere hydrological model with three layered energy balance snow melt module (WEB-DHM-S) has been implemented at point scale at Yagisawa dam site to evaluate the long-term simulation of snow depth from 1948 to 2006 using high resolution JP10 reanalysis data. The time series of snow depth, its averaged value and anomaly and the snow cover duration are evaluated. The model is able to capture the seasonal and inter-annual variability of snow depth well with average bias at $0.013 \mathrm{~m}$ and root mean square error at $0.29 \mathrm{~m}$. A continuous negative anomaly was well simulated from 1985 to 1994. Long-term analysis showed that the decadal change was more apparent for snow cover days with snow depth above $50 \mathrm{~cm}$ and the number of snowfall days had a decreasing trend. In addition, the snow depth values from 1948 to 1963 , an outcome of this research, can be used as the reference dataset by the scientific community.
\end{abstract}

Key Words: WEB-DHM-S, energy balance, Yagisawa, snow depth, JP10 reanalysis, longterm

\section{INTRODUCTION}

The energy and water balance in cold regions are highly modulated by the presence of seasonal snow cover due to its intrinsic properties like high albedo, low thermal conductivity and large water storage capacity. The variability in the magnitude and timing of snowfall, the evolution of snow depth following compaction and melt controls the length of snow cover duration which in turn influences the temporal variability of spring snowmelt runoff. These variabilities can also modulate the response of soil towards surface warming. Snow cover and its year to year variability is the reflection of winter climate variability ${ }^{1)}$. Long-term trend of snow cover variability is of great importance as it plays an important role in analyzing runoff prognoses and climate modeling systems ${ }^{2)}$.

Modeling the long-term variability of snow cover with the use of reanalysis dataset is very much important as long-term forcing dataset may not be available at all the regions. Reanalysis climate datasets are prepared by a diagnostic atmospheric model run with a fixed dynamical core, physical parameterizations and data assimilation system ${ }^{3}$. Many reanalysis products such as ERA-404), ERA-Interim $^{5)}, \mathrm{JRA}^{2} 5^{6)}$ and NCEP/NCAR ${ }^{7}$ have been developed by different institutions and these dataset are used by many scientists in atmospheric and hydrological modeling works. However, the use of reanalysis dataset in studying the inter-annual variability of snow characteristics is very limited ${ }^{8)}$ due to its coarse resolution. Recently, a high resolution $(10 \mathrm{~km})$ reanalysis dataset over Japan has been developed for 1948 to 2006, referred as JP10 at 
the Scripps Institute of Oceanography, USA.

This work is unique in the extent of the application of the JP10 reanalysis data in simulating the inter-annual variability of snow cover with the use of physically based three layered energy balance snow model (WEB-DHM-S). WEB-DHM-S has shown its capability in capturing the snow processes accurately in both point ${ }^{9)}$ and basin scale ${ }^{10)}$ at wide variety of climatic regions. This paper aims to provide insight into the features of the long-term snow cover changes and variability at Yagisawa dam site of Upper Tone River in Japan. Variability in snowmelt runoff is very much important in Upper Tone region since this region supplies drinking water to about 29 million people in the Tokyo metropolitan area.

\section{STUDY AREA AND DATA}

The study area is Yagisawa dam site, located north east of Tokyo in Upper Tone River, Japan (see Fig. 1). It is a medium-elevation open site (latitude $139.054^{\circ}$ and longitude $36.912^{\circ}$ ) at $870 \mathrm{~m}$ above mean sea level. Climate condition in this region is wet and humid. February is the coldest month, with a mean temperature of $-3^{\circ} \mathrm{C}$, and August is the warmest month, with temperatures averaging $20^{\circ} \mathrm{C}$. Heavy snowfall is common in winter (December to February), owing to a northwest monsoon wind from the Sea of Japan. The mean annual winter precipitation (snowfall) is about $900 \mathrm{~mm}$. A continuous snow cover exists from early November to late April. The site experiences deep snow depth with the maximum value of about $3.5 \mathrm{~m}$. Yagisawa dam is an important regulator of snowmelt runoff in spring, and flooding in summer.

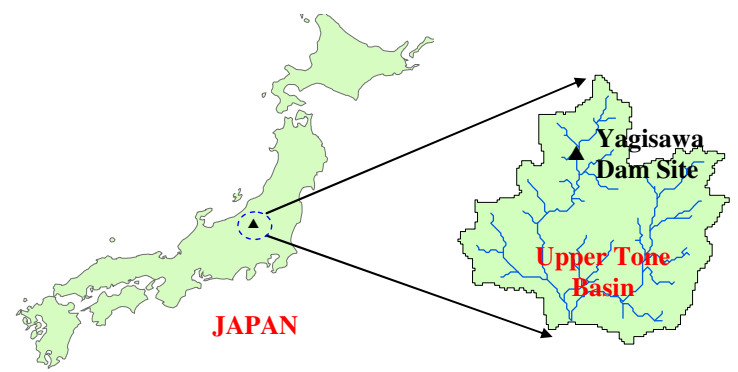

Fig. 1 Location of Yagisawa dam site

Meteorological parameters (including precipitation) have not been measured at the site, however daily averaged snow depth measurements are available from 1964 onwards. The atmospheric forcing data required to drive the snow model are surface air temperature, surface air pressure, specific humidity, wind speed, shortwave and longwave radiation which were obtained from JP10 reanalysis dataset. JP10 is a $10-\mathrm{km}$ and hourly dynamically downscaling simulation [The Scripps version of Regional Spectral
Model $\left.\quad(\mathrm{RSM})^{11)}\right]$ dataset from NCEP/NCAR Reanalysis over Japan for 1948-2006. The data is produced in Earth Simulator Center with the Earth Simulator at Scripps Institution of Oceanography, USA. JP10 dataset are made freely available to the public and the scientific community through the Data Integration and Analysis System (DIAS) ${ }^{12}$.

\section{METHODS}

\section{(1) Snow Model}

The snow model applied in this study is the WEB-DHM-S (Water and Energy Budget - based Distributed Hydrological Model with improved snow physics) ${ }^{9,10)}$ which can simulate the variability of snow density, snow depth and snow water equivalent, liquid water and ice content, snow albedo, snow layer temperature and thermal heat due to conduction more accurately through the physically based energy balance modeling approach. WEB-DHM-S is the improved version of WEB-DHM ${ }^{13)}$ in its snow physics which has been developed by coupling the snow physics of Simplified Simple Biosphere Model version $3(\mathrm{SSiB} 3)^{14)}$ and albedo physics of Biosphere-Atmosphere-Transfer-Scheme(BATS) ${ }^{15}$.

In WEB-DHM-S, the snowpack is initially divided into three layers that start with the same initial snow temperatures. The top layer thickness is kept at a fixed depth of $2 \mathrm{~cm}$ regardless of the total snow depth to provide reasonable simulation of the diurnal changes in the snow surface temperature. The maximum thickness of the middle layer is kept at $20 \mathrm{~cm}$, and the bottom layer represents the remaining body of the snowpack. Enthalpy is used as the prognostic variable in energy balance calculations. The heat budget of top layer is controlled by surface energy balance where that of the second and third layers is controlled by the heat conduction and penetrated shortwave radiation. Moreover, the heat budget of the bottom layer is added by the conduction from the ground heat flux. The mass budget for each snow layer is calculated accordingly by taking account of the precipitation, direct throughfall, drip fall, evaporation, condensation, compaction, liquid water retention, snowmelt runoff and infiltration into the underlying layers. The snow albedo over ground surface is parameterized using a physically based prognostic snow albedo scheme of the BATS ${ }^{15}$. The snow albedo is computed for visible (VIS) and near infra red (NIR) spectral bands with adjustments for illumination angle and snow age. Fresh-snow albedo in the VIS and NIR bands are kept at 0.85 and 0.65 respectively. Three snow compaction processes, namely destructive metamorphism, densification due to snow overburden and compaction due to snow 
melting, are parameterized following Anderson ${ }^{16}$. The bulk density of ice for new snowfall is calculated following the formulation used in the CROCUS snow model ${ }^{17)}$. Details of the model equations and snow physics can be found in Shrestha et al. ${ }^{9,10)}$.

The threshold air temperature for differentiation of precipitation into the solid and liquid form is an important parameter as it determines whether water is available for runoff and infiltration or for snow accumulation $^{18)}$. Motoyoma ${ }^{19)}$ reported that this temperature is between $1^{\circ} \mathrm{C}$ and $3^{\circ} \mathrm{C}$ in central Japan. This study uses $2^{\circ} \mathrm{C}$ as the hourly threshold air temperature, below which all precipitation is assumed snowfall and above which it is assumed rainfall.

\section{(2) Bias Correction of JP10 reanalysis}

Reanalysis products may offer large amount of biases that can result in unrealistic estimates of energy, mass, and momentum exchanges between the land surface and atmosphere ${ }^{20)}$. JP10 data also offer biases in meteorological forcing. These biases are assessed by comparing the JP10 forcing with the forcing prepared by Wang et al. ${ }^{21)}$ for 2000-2004. A ratio-based approach is employed for the correction of shortwave radiation and precipitation where a difference-based approach is employed for the correction of air temperature, wind speed, longwave, humidity and pressure. The four year average of the biases in all meteorological forcing were applied to correct the long-term JP10 dataset (1948-2006).

\section{(3) Simulation Setup}

The model simulation setup is designed for 57 hydrological years from November 1948 to November 2006. The time series of snow depth, its averaged value and anomaly, the time period during which the ground is continuously covered with snow for snow depth above $10 \mathrm{~cm}, 30 \mathrm{~cm}, 50 \mathrm{~cm}$ and $70 \mathrm{~cm}$ are analyzed. The snow depth responsible for 100 days continuous snow cover is also estimated. Moreover, trends on daily snowfall are analyzed for long-term changes. The number of days with snowfall above $1 \mathrm{~cm}, 2 \mathrm{~cm}, 3 \mathrm{~cm}$ and 5 $\mathrm{cm}$ are also investigated. The model performance in simulating the snow depth is evaluated by Mean Bias Error (MBE) and Root Mean Square Error (RMSE), defined as followings;

$$
\begin{aligned}
& M B E=\sum_{i=1}^{n}\left(S_{i}-O_{i}\right) / n \\
& R M S E=\sqrt{\sum_{i=1}^{n}\left(S_{i}-O_{i}\right)^{2} / n}
\end{aligned}
$$

where $n$ is the total number of time series for each snow season that very year-by-year, $S_{i}$ is the simulation result and $O_{i}$ is the observed data.

\section{RESULTS AND DISCUSSIONS}

\section{(1) Snow depth simulation (1948-2006)}

Fig. 2 demonstrates the comparison of time series of simulated and measured snow depth. The simulation results are from November 1948 to November 2006 where measured snow depth data are available from 1964 only. Graphs of simulated versus measured daily snow depth reveal that the model captures inter-annual variability of snow cover well with MBE at $0.013 \mathrm{~m}$ and RMSE at $0.29 \mathrm{~m}$ (averaged value for 1964-2006). However, large biases are simulated in some years [e.g. underestimations in $1964(-0.43 \mathrm{~m}), 1984(-0.33 \mathrm{~m}), 2005(-0.31 \mathrm{~m})$ and $2006(-0.49 \mathrm{~m})$ and overestimations in $1968(+0.45 \mathrm{~m})$, $1970(+0.33 \mathrm{~m}), 1976(+0.32 \mathrm{~m})$ see Table 1].

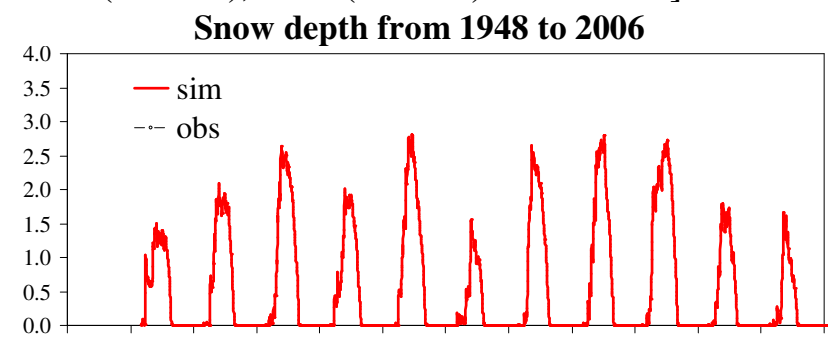

$\begin{array}{lllllllllllll}\text { S-47 } & \text { S-48 } & \text { S-49 } & \text { S-50 } & \text { S-51 } & \text { S-52 } & \text { S-53 } & \text { S-54 } & \text { S-55 } & \text { S-56 } & \text { S-57 } & \text { S-58 } & \text { S-59 }\end{array}$
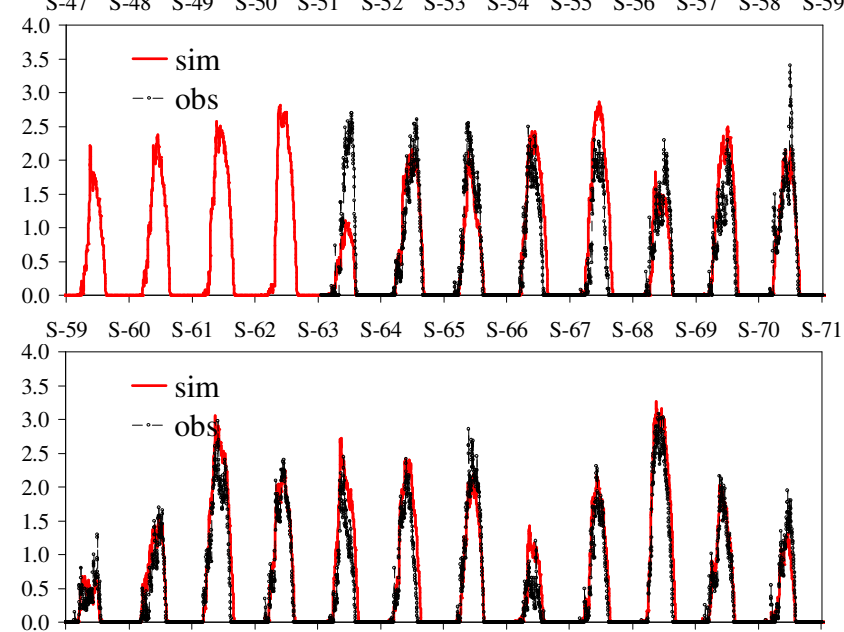

$\begin{array}{lllllllllllll}\text { S-71 } & \text { S-72 } & \text { S-73 } & \text { S-74 } & \text { S-75 } & \text { S-76 } & \text { S-77 } & \text { S-78 } & \text { S-79 } & \text { S-80 } & \text { S-81 } & \text { S-82 } & \text { S-83 }\end{array}$

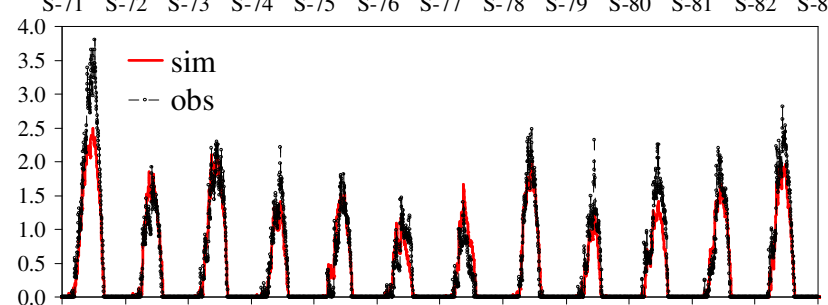

$\begin{array}{lllllllllllll}\text { S-83 } & \text { S-84 } & \text { S-85 } & \text { S-86 } & \text { S-87 } & \text { S-88 } & \text { S-89 } & \text { S-90 } & \text { S-91 } & \text { S-92 } & \text { S-93 } & \text { S-94 } & \text { S-95 }\end{array}$

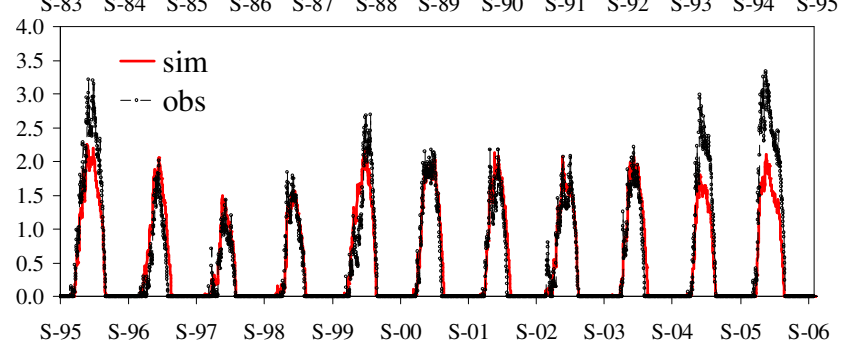

Fig. 2 Simulated and observed daily snow depth (m) from 1948 to 2006, S-47 refers to September 1947. 
Table $1 \mathrm{MBE}(\mathrm{m})$ and RMSE for Snow depth (1964-2006)

\begin{tabular}{ccc|ccc|ccc}
\hline Year & MBE RMSE & \multicolumn{2}{c|}{ Year } & \multicolumn{2}{c|}{ MBE } & RMSE & Year & \multicolumn{2}{c}{ MBE RMSE } \\
\hline 1964 & -0.43 & 0.77 & 1979 & +0.18 & 0.32 & 1994 & -0.02 & 0.19 \\
1965 & +0.08 & 0.28 & 1980 & +0.14 & 0.24 & 1995 & -0.14 & 0.24 \\
1966 & -0.16 & 0.27 & 1981 & +0.24 & 0.35 & 1996 & -0.27 & 0.41 \\
1967 & +0.26 & 0.43 & 1982 & +0.07 & 0.15 & 1997 & +0.20 & 0.31 \\
1968 & +0.45 & 0.66 & 1983 & -0.10 & 0.24 & 1998 & +0.08 & 0.15 \\
1969 & -0.06 & 0.34 & 1984 & -0.33 & 0.51 & 1999 & -0.01 & 0.11 \\
1970 & +0.33 & 0.48 & 1985 & +0.07 & 0.17 & 2000 & 0.00 & 0.41 \\
1971 & -0.02 & 0.27 & 1986 & 0.00 & 0.18 & 2001 & +0.04 & 0.15 \\
1972 & -0.02 & 0.14 & 1987 & -0.09 & 0.20 & 2002 & +0.10 & 0.22 \\
1973 & +0.09 & 0.22 & 1988 & +0.01 & 0.15 & 2003 & +0.02 & 0.11 \\
1974 & +0.26 & 0.38 & 1989 & -0.05 & 0.20 & 2004 & +0.11 & 0.21 \\
1975 & +0.05 & 0.14 & 1990 & +0.13 & 0.21 & 2005 & -0.31 & 0.48 \\
1976 & +0.32 & 0.47 & 1991 & -0.03 & 0.15 & 2006 & -0.49 & 0.68 \\
1977 & +0.24 & 0.38 & 1992 & -0.11 & 0.22 & & & \\
1978 & -0.11 & 0.23 & 1993 & -0.16 & 0.29 & & & \\
\hline
\end{tabular}

These biases are mainly associated with the large variation in precipitation of JP10 reanalysis. We shall investigate the atmospheric features of JP10 in future for identifying the biases in particular year. Fig. 3a shows the average annual snow depth for simulated and observed values. The long-term average is calculated based on observations from 1964 to 2006, and is estimated as $1.15 \mathrm{~m}$. The simulated values fairly agree with the observations with coefficient of correlation at 0.75 . Long-term trend shows that the average snow depth has slightly negative trend. From the analysis of the 10 year trend, it is found that the trend is fairly stable from 1954 through 1963, decreasing from 1964 to 1993 and increasing afterwards.

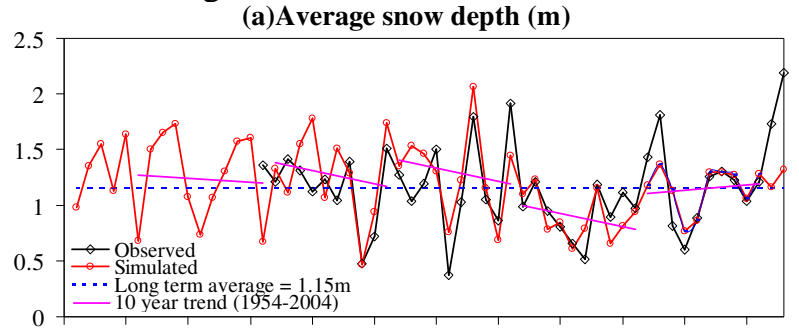

$\begin{array}{llllllllllll}1948 & 1953 & 1958 & 1963 & 1968 & 1973 & 1978 & 1983 & 1988 & 1993 & 1998 & 2003\end{array}$ (b)Anomaly in average snow depth (m)

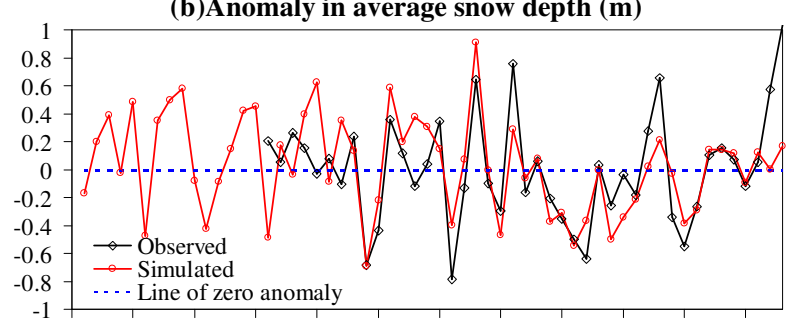

$\begin{array}{llllllllllll}1948 & 1953 & 1958 & 1963 & 1968 & 1973 & 1978 & 1983 & 1988 & 1993 & 1998 & 2003\end{array}$ (c) Maximum snow depth (m)

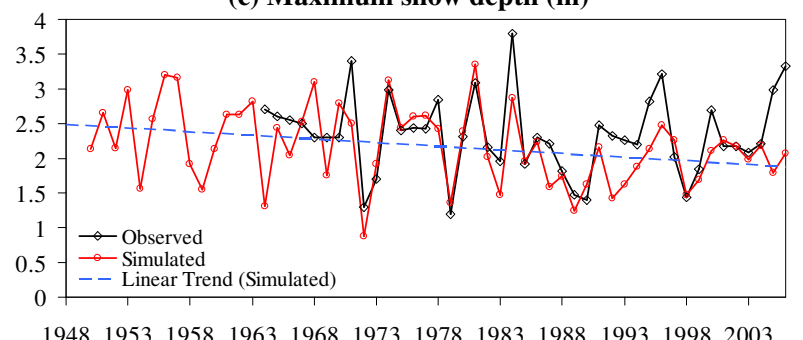

$\begin{array}{llllllllllll}1948 & 1953 & 1958 & 1963 & 1968 & 1973 & 1978 & 1983 & 1988 & 1993 & 1998 & 2003\end{array}$

Fig. 3 Simulated and observed annual (a) average snow depth (m), (b) their anomalies (m) and (c) Maximum snow depth (m). Year 1948 in X-axis indicates the year1947/48
The long-term simulations since 1948 shows that a negative anomaly (above $0.5 \mathrm{~m}$ ) is simulated about every five years till 1964 . The negative anomaly of about $0.7 \mathrm{~m}$ is observed after 8 years from 1964 to 1979 (see Fig. 3b). The simulated anomaly matches quite well in 1972; however, a large underestimation is simulated in 1979. From 1978 through 1984, both observed and simulated values demonstrate very sharp anomalous conditions. From 1985 to 1994, the negative anomalous condition continued for 9 consecutive years with comparatively strong negative trend which indicates remarkable drought condition. The simulated maximum snow depth values fairly agree with the observations with coefficient of correlation at 0.70 (see Fig. 3c). Negative trend for maximum snow depth is speculated following the results of average snow depth.

\section{(2) Number of Days with Snow cover}

Time series of simulated and observed snow cover days for different snow depth thresholds (10 $\mathrm{cm}, 30 \mathrm{~cm}, 50 \mathrm{~cm}$ and $70 \mathrm{~cm}$ ) are shown in Fig. 4(a-d). The snow depth at $30 \mathrm{~cm}, 50 \mathrm{~cm}$ and above $70 \mathrm{~cm}$ is considered as sufficient, good and excellent condition for skiing respectively. The long-term average snow cover days from observations (1964-2006) for these thresholds are calculated at 133 days, 120 days, 108 days and 96 days where these values are overestimated by 8 days for simulated one (1948-2006). However, observed and simulated trend agree fairly well with coefficient of correlation at 0.77 . Observations show that at least $65 \mathrm{~cm}$ of snow depth is available for continuous 100 days which seems very good for ski resort. This depth is at $75 \mathrm{~cm}$ for simulation result. No long-term change in the trend for snow cover days is found where decadal change is evident for higher value of threshold (above $50 \mathrm{~cm}$ and $70 \mathrm{~cm}$ ).

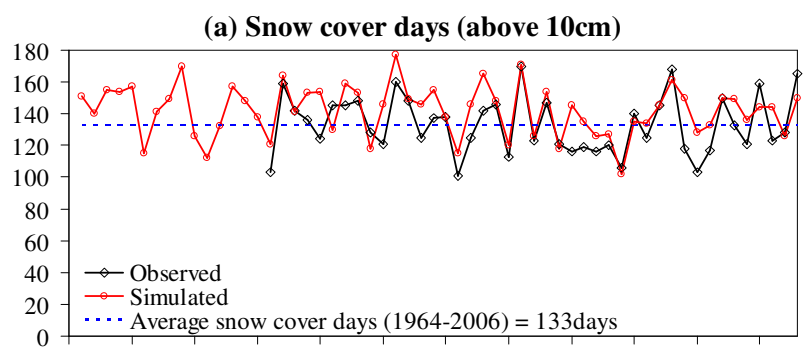

$\begin{array}{llllllllllll}1948 & 1953 & 1958 & 1963 & 1968 & 1973 & 1978 & 1983 & 1988 & 1993 & 1998 & 2003\end{array}$ (b) Snow cover days (above $30 \mathrm{~cm}$ )

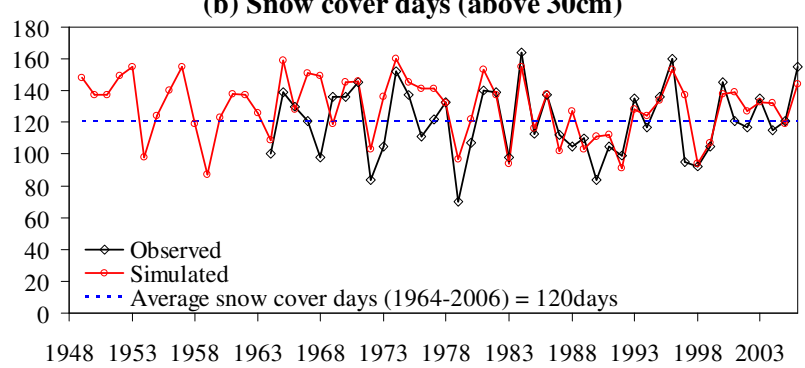


(c) Snow cover days (above $50 \mathrm{~cm})$

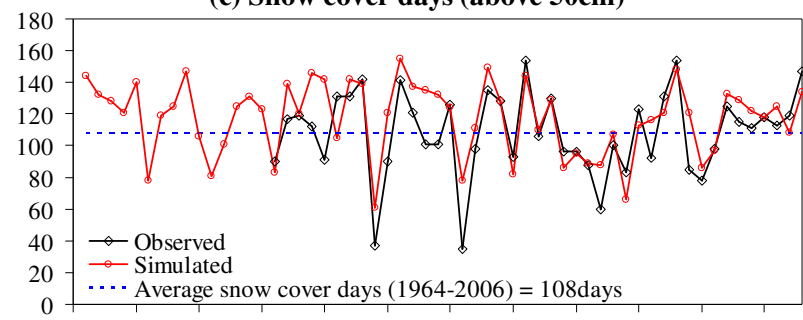

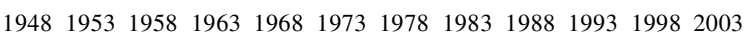
(d) Snow cover days (above $70 \mathrm{~cm})$

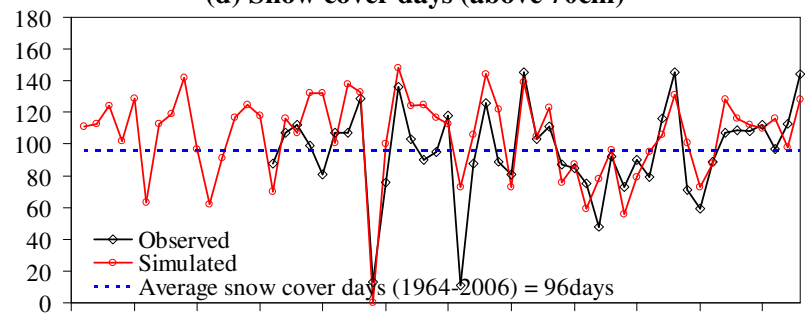

194819531958196319681973197819831988199319982003

Fig. 4 Inter-annual variability of simulated and observed snow cover days above (a) $10 \mathrm{~cm}$ (b) $30 \mathrm{~cm}$ (c) $50 \mathrm{~cm}$ and (d) $70 \mathrm{~cm}$

\section{(3) Number of Days with Snowfall}

Time series of the number of days with snowfall above $1 \mathrm{~cm}, 2 \mathrm{~cm}, 3 \mathrm{~cm}$ and $5 \mathrm{~cm}$ is demonstrated in Fig. 5. The long-term averages of the number of days with aforementioned thresholds are about 28, 10, 4 and 0.4 respectively. The linear trends are analyzed for two long-term periods; one is simulation period (1948-2006) and the other is the observation period (1964-2006). The trend for number of days above 1 $\mathrm{cm}$ is strongly negative for 1948-2006 and matches with the trend for 1964-2006. The trends for other thresholds for 1964-2006 are milder than that for 1948-2006; however, both trends indicate decreasing tendency. A sharp boundary could be found towards rapid decrease in number of snowfall days, which is after $1985 / 86$. In recent years, the number of snowfall days has increasing tendency since 1998. Although, the observed snowfall data are in depth (thickness), not in water equivalent, we attempted to compare the simulated results with observations for snowfall days above $1 \mathrm{~cm}$ by employing a snow density of $80 \mathrm{kgm}^{-3}$ to convert observed snowfall depth to water equivalent. As shown in Fig. 5, the simulated values match satisfactorily with the observations despite of remarkable discrepancies in some years.

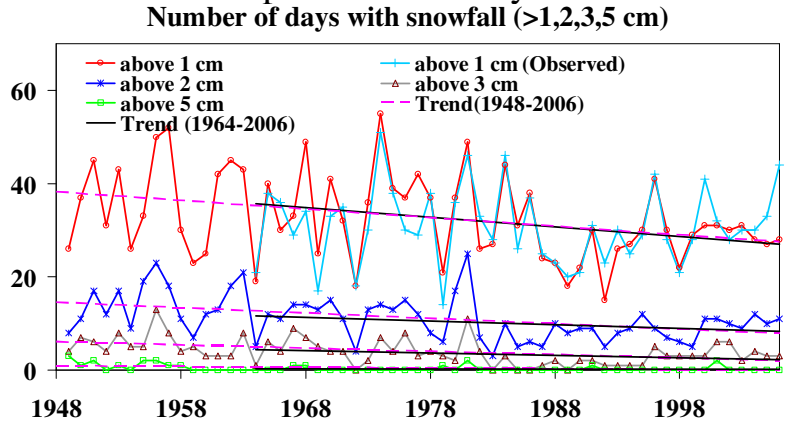

Fig. 5 Inter-annual variability and trend for number of days with snowfall above $1 \mathrm{~cm}, 2 \mathrm{~cm}, 3 \mathrm{~cm}$ and $5 \mathrm{~cm}$

\section{4) Correlation of snow depth with temperature and snowfall}

Fig. 6 illustrates the temporal variability of the annual snowfall sums for 1948-2006 and indicates a decreasing trend. Accumulated snow depth is highly correlated with snowfall (Correlation coefficient at 0.96). Significant negative trend of the accumulated snowfall indicates decrease of average snow depth, and continuous snow cover duration, as mentioned earlier. The variability in snowfall and average snow depth are well supported by the variability in winter temperature [averaged of December-JanuaryFebruary (DJF)]. The higher the DJF value, the lower the snowfall and snow depth and vice versa (not shown here). However, in some years, decrease in snow depth despite increasing snowfall is probably due to increased temperature during melting season.

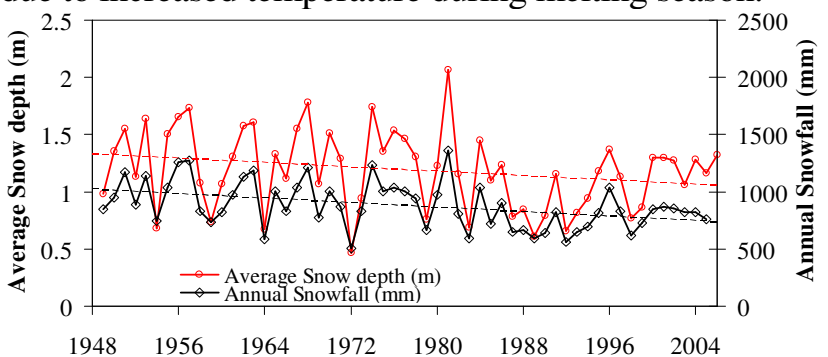

Fig. 6 Inter-annual variability and trend for annual snowfall sum $(\mathrm{mm})$ and average snow depth $(\mathrm{m})$

Moreover, the inter-annual variability of the ratio of snowfall to total precipitation with respect to air temperature in the time slot of November-March is also investigated (see Fig. 7). It is demonstrated that this ratio has increasing trend till 1985/86 which is in accordance with the decreasing trend of air temperature. After 1986, there exist sharp increasing tendency in air temperature which in turn causes decreasing trend of the ratio of snowfall to total precipitation. This finding clearly identifies the evidence of impact of climate change after late 80s.

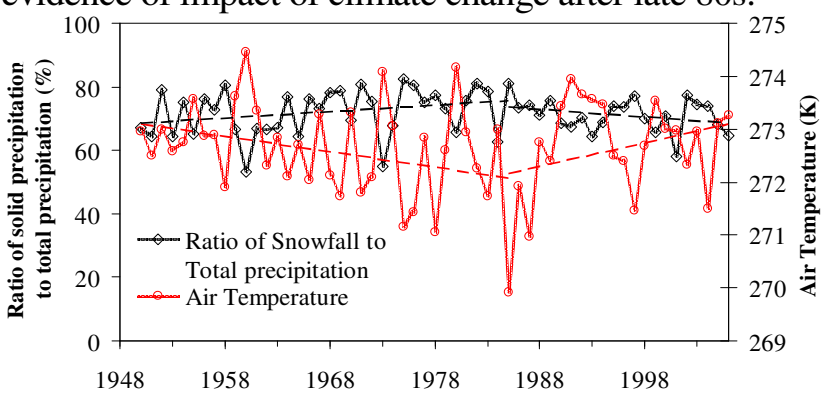

Fig. 7 Inter-annual variability and trend for ratio of solid precipitation to the total precipitation (in \%) and average air temperature (K) in November-May

Previous studies about the long-term trend of observed snow depth, continuous snow cover days and snowfall around this region also showed the decreasing trend ${ }^{22,23}$. The high negative correlation of snowfall to air temperature in this study is supported by the results of Takeuchi et al. ${ }^{24)}$. However, more research on basin to regional scale should be carried out in this region. 


\section{CONCLUSIONS}

In this study, the three layered energy balance based snow melt model (WEB-DHM-S) has been implemented at point scale at Yagisawa dam site to evaluate the long-term simulation of snow depth for 1948-2006 using high resolution JP10 reanalysis dataset. The model is able to capture the seasonal and interannual variability of snow depth well with average bias at $0.013 \mathrm{~m}$ and RMSE at $0.29 \mathrm{~m}$. The time series of snow depth, its maximum and averaged value and the snow cover durations are evaluated. From 1985 to 1994, the negative anomalous condition for 9 consecutive years with comparatively strong negative trend was well simulated by the model. The observed and simulated trends for the snow cover duration of snow depth above 10, 30, 50 and $70 \mathrm{~cm}$ agree fairly well with coefficient of correlation at 0.77 . Observations show that at least $65 \mathrm{~cm}$ of snow depth is available for continuous 100 days which seems very good for ski resort. This depth is at $75 \mathrm{~cm}$ for simulation. No long-term change in the trend for snow cover days is found where decadal change is evident for higher value of threshold (above $50 \mathrm{~cm}$ and $70 \mathrm{~cm}$ ). The long-term $(57$ year) average annual snowfall is estimated at $880 \mathrm{~mm}$. The linear trend for the number of snowfall days is decreasing. In addition, the snow depth values from 1948 to 1963 , an outcome of this research, can be used as the reference dataset by the scientific community. A future step for this research would be application of JP10 reanalysis products in basin scale for the assessment of long-term snow hydrology in managing the water resources in integrated river basin management approach.

ACKNOWLEDGMENT: This study was supported by the grants from the Ministry of Education, Culture, Sports, Science \& Technology (MEXT) of Japan, and was implemented within the Research Program on Climate Change Adaptation (RECCA). The authors express deep gratitude to Data Integration Analysis System (DIAS) project 2011-2015 for providing the JP10 dataset.

\section{REFERENCES}

1) Falarz, M.: Variability and trends in the duration and depth of snow cover in Poland in the $20^{\text {th }}$ century, Int. J. Climatol., Vol. 24, pp.1713-1727, 2004.

2) Laternser, M. and Schneebeli, M.: Long term snow climate trends of the swiss alps (1931-99), Int. J. Climatol., Vol. 23, pp.733-750, 2003.

3) Castro, and coauthors: Investigation of the summer climate of the contiguous United States and Mexico using the regional atmospheric modeling system (RAMS). Part I: Model Climatology (1950 - 2002), J. Climate, Vol. 20, pp.3844-3864, 2007.

4) Uppala, S. M., and coauthors: The ERA-40 reanalysis, $Q$. J. R. Meteorol. Soc., Vol. 131(612), 2961-3012, 2005.

5) Dee, D. P., and coauthors: The ERA - Interim reanalysis: Configuration and performance of the data assimilation system, Q. J. R. Meteorol. Soc., Vol. 137(656), pp.553-597, 2011.
6) Onogi, K., and Coauthors: The JRA-25 reanalysis, $J$. Meteor. Soc. Japan, Vol. 85, pp.369-432, 2007.

7) Kistler, R., and coauthors: The NCEP-NCAR 50-Year Reanalysis:Monthly means CD - ROM and documentation. Bull.Amer. Meteor. Soc., Vol. 82, pp.247-267, 2001.

8) Khan, V., and coauthors: Snow cover characteristics over the main Russian river basins as a represented by reanalyses and measured data, J. App. Meteorol. Climatol., Vol. 47, pp.1819-1833, 2008.

9) Shrestha, M., and coauthors: Improving the snow physics of WEB-DHM and its point evaluation at the SnowMIP sites, Hydrol. Earth Syst. Sci., Vol. 14, pp.2577-2594, 2010.

10) Shrestha, M., and coauthors: Modeling the spatial distribution of snow cover in the Dudhkoshi region of Nepal Himalayas, J. Hydrometeor., Vol. 13(2), pp.204-222, 2012.

11) Kanamitsu, M., and coauthors: Parallel implementation of the regional spectral atmospheric model, CEC Report, 2005.

12) Kinutani, H., and coauthors: The DIAS data release and its cross-disciplinary usage, JGU Meeting, ACG36-P08, 2012.

13) Wang, L., and coauthors: Development of a distributed biosphere hydrological model and its evaluation with the Southern Great Plains Experiments (SGP97 and SGP99), J. Geophys. Res.-Atmos., Vol. 114, D08107, 2009.

14) Xue, Y., Sun, S., Kahan, D. S. and Jiao, Y.: Impact of parameterizations in snow physics and interface processes on the simulation of snow cover and runoff at several cold region sites, J. Geophy. Res. -Atmos., Vol. 108(D22), 2003.

15) Yang, Z.-L., and coauthors: Validation of the snow submodel of the Biosphere-Atmosphere Transfer Scheme with Russian snow cover and meteorological observational data, J. Climate., Vol. 10, pp.353-373, 1997.

16) Anderson, E. A., 1976: A point energy and mass balance model of a snow cover, NOAA Tech. Rep. NWS 19, U.S. Dept. of Commerce, Washington, DC, $150 \mathrm{pp}$.

17) Brun, E., and coauthors: An energy and mass model of snow cover suitable for operational avalanche forecasting, $J$. Glaciol., Vol. 35, pp.333-342, 1989.

18) Kienzle, S.W.: A new temperature based method to separate rain and snow, Hydrol. Processes., Vol. 22, pp.5067-5085, 2008.

19) Motoyama, H.: Simulation of seasonal snowcover based on air temperature and precipitation. J. App. Meteorol., Vol. 29, pp.1104-1110, 1990.

20) Berg, A. A., and coauthors: Impact of bias correction to reanalysis products on simulations of North American soil moisture and hydrological fluxes, J. Geophys. Res., Vol. 108(D16), 4490, 2003.

21) Wang, L., Koike, T., Yang, K. and Yeh, P. : Assessment of a distributed biosphere hydrological model against streamflows and MODIS land surface temperature in the upper Tone river basin, J. Hydrol., Vol. 377, pp.21-34, 2009.

22) Hiroto, S.: Long-term Changes in Snowfall Depth and Snowcover Depth in and around Niigata Prefecture from 1927 to 2005: Analysis Using Data Observed at Railway Stations, Tenki, Vol. 53(3), pp. 185-196, 2006.

23) Yamaguchi, S., Abe, O., Nakai, S. and Sato, A.: Recent fluctuations of meteorological and snow conditions in Japanese mountains, Ann. Glaciol, Vol. 52(56), pp. 209-215, 2011.

24) Takeuchi, Y., Endo, Y., and Murakami, S.: High correlation between winter precipitation and air temperature in heavy-snowfall areas in Japan, Ann. Glaciol, Vol. 49(1), pp. 7-10(4), 2008.

(Received September 30, 2012) 